\title{
Perspectivas sobre as tendências e desafios da agricultura periurbana de Porto Alegre
}

\author{
Deise de Oliveira Alves ${ }^{1}$ \\ Glauco Schultz ${ }^{2}$ \\ Leticia de Oliveira ${ }^{3}$
}

Submissão: 31/08/2021 Aceite: 30/09/2021

\begin{abstract}
Resumo
A agricultura periurbana de Porto Alegre/RS apresenta uma importante produção rural de hortigranjeiros que são desenvolvidas em áreas com significativo patrimônio natural. Pensando nisso, foi aprovado o projeto de lei que institui e define como Zona Livre de Agrotóxicos à Produção Primária e Extrativa até o ano de 2032. Portanto, a pesquisa teve como objetivo analisar as tendências de desafios da agricultura periurbana de Porto Alegre/RS. Os dados foram obtidos por meio de entrevistas semiestruturadas junto aos agricultores, e analisados mediante análise de conteúdo. Concernente aos desafios e perpectivas para o futuro da agricultura orgânica, percebeu-se otimismo por parte de alguns agricultores frente ao crescimento da preocupação da população em relação ao consumo de alimentos saudáveis. Um fator preocupante corresponde a sucessão futura, pois são poucos os agricultores que criaram seus filhos na atividade. Em relação aos objetivos e metas estabelecidos pelos agricultores, percebe-se que os agricultores que pretendem continuar na atividade e manterem-se no negócio, tentam maximizar a produção, desenvolver produtos novos, inovar os métodos produtivos, agregar valor ao produto, expandir seus negócios em novos canais de comercialização e criar relações solidárias com os consumidores.
\end{abstract}

Palavras-chave: Produção de alimentos. Cidade. Agricultura orgânica. Patrimônio natural.

\section{Perspectives on the trends and challenges of periurban agriculture in Porto Alegre}

\begin{abstract}
The periurban agriculture of Porto Alegre-RS, presents an important rural production of horticultural crops that are developed in areas with significant natural heritage. With this in mind, the bill that institutes and defines the Pesticide-Free Zone for Primary and Extractive Production until 2032 was approved. Therefore, the research aimed to analyze the trends of challenges in periurban agriculture in Porto Alegre-RS. Data were obtained through semistructured interviews with farmers and analyzed through content analysis. Concerning the challenges and perspectives for the future of organic agriculture, optimism was perceived on the part of some farmers regarding the growing concern of the population in relation to the consumption of healthy foods. Another worrying factor is the future succession, as few farmers raised their children in the activity. In relation to the objectives and goals established by the farmers, it is clear that farmers who intend to continue in the activity and remain in business, try to maximize production, develop new products, innovate production methods, add value to the product, expand their business in new sales channels and create solidary relationships with consumers.
\end{abstract}

Keywords: Food production. City. Organic agriculture. Natural patrimony.

\section{Introdução}

O aumento da população urbana e a expansão das áreas metropolitanas em todo o mundo exigem a maximização da produtividade do setor agrícola, a fim de atender à crescente demanda por alimentos. Em 2008, a população urbana mundial superou, em número, a

\footnotetext{
${ }^{1}$ Doutoranda em Agronegócios (CEPAN-UFRGS). E-mail: deiseoliveiraalves@hotmail.com

${ }^{2}$ Doutorado em Agronegócios (CEPAN-UFRGS). Professor do PPG em Desenvolvimento Rural (PPGDR) e do PPG em Agronegócios (CEPAN), da UFRGS. E-mail: glauco.schultz@ufrgs.br

${ }^{3}$ Doutorado em Agronegócios (CEPAN-UFRGS). Professora da Universidade Federal do Rio Grande do Sul (UFRGS).

E-mail: leticiaoliveira@ufrgs.br
} 
população rural pela primeira vez na história. Até 2030 , espera-se que $60 \%$ da população do planeta esteja vivendo nas cidades. Conquanto, tal processo de urbanização relaciona-se intimamente com o crescimento da pobreza urbana e da insegurança alimentar (FAO, 2021).

De acordo com o relatório do Centro Regional de Informações das Nações Unidas-UNRIC (2017), a maximização da demanda alimentar devido ao crescimento populacional, migração urbana e outros fatores, exigirá que os países aumentem a sua produtividade agrícola, advertindo ainda que sem a elevação da oferta de alimentos, os preços vão subir significativamente. Além disso, o crescimento da produção agrícola diminuirá para uma média de $1,7 \%$ anualmente nos próximos 10 anos, e consequentemente, aumentara as restrições de recursos e pressões ambientais (UNRIC, 2017).

Como alternativa para minimizar esses problemas o desenvolvimento da agricultura urbana e periurbana corresponde à uma das principais estratégias que está sendo adotada por diferentes países, visando combater a pobreza urbana e melhorar o bem-estar dos moradores das cidades em constante crescimento populacional (ORSINI et al., 2013). Para tanto, integram o crescimento de plantas e a criação de animais dentro e ao redor das cidades e em pequenas áreas, tais como quintais, terraços, pátios, ou ainda, em hortas urbanas - espaços comunitários ou espaços públicos não urbanizados (PIRES, 2016; DUZí et al., 2017).

Os objetivos da agricultura urbana e periurbana, muitas vezes, vão além da produção e fornecimento de alimentos, sob uma perspectiva sustentável, estão geralmente relacionados às contribuições sociais, econômicas e ambientais para o sistema urbano, tornando esse tipo de agricultura multifuncional (CAMPBELL, 2004; ORSINI et al., 2014; SPECHT et al., 2014). Além disso, os papéis sociais dessa prática podem envolver, principalmente, recreação, educação, saúde, assistência social e coesão (CHOU et al., 2017). A multifuncionalidade fortalece a base econômica, evitando o abandono da terra e a agricultura como uma alternativa economicamente razoável e competitiva ao desenvolvimento urbano (ZASADA, 2018).

A agricultura multifuncional abrange várias estratégias e campos de atividades na propriedade, tais como: diversificação dentro e fora da propriedade, especialização em produção e processamento, marketing direto ou medidas na natureza e manejo da paisagem (ORSINI et al., 2014). Essa agricultura multifuncional é vista na cidade de Porto Alegre, localizada na Macrozona 8, região sul da cidade. Essa região se caracteriza-se como agricultura periurbana que apresenta uma importante produção rural de hortigranjeiros, desenvolvida em áreas que se intercalam com vários núcleos de habitação urbana. Esta macrozona também tem 
importância pelo seu significativo patrimônio natural, e sua preservação implica na manutenção da qualidade da cidade como um todo (PORTO ALEGRE, 2012).

Diante do significativo patrimônio natural da cidade, no ano de 2017 foi aprovado o projeto de Lei no 12.328, que institui e define como Zona Livre de Agrotóxicos à Produção Primária e Extrativa a área definida como Zona Rural no Município de Porto Alegre até o ano de 2032. Esse projeto de lei definiu em 15 anos o prazo para a conversão de toda produção agrícola convencional em orgânica. Portanto, dada a importância da agricultura periurbana como forma de garantir a segurança alimentar da população, e, também, considerando a produção orgânica para uma alimentação saudável e preservação ambiental, torna-se relevante um estudo que contemple as tendências de desafios da agricultura periurbana de Porto Alegre/RS.

\section{Caracterização da agricultura urbana e periurbana}

A segurança alimentar urbana requer um suprimento constante de alimentos nutritivos e seguros durante todo o ano. Os consumidores urbanos geralmente dependem de alimentos adquiridos principalmente das áreas rurais ou ainda importados para o país. Assim, a produção de alimentos em áreas urbanas e periurbanas configuram-se como uma alternativa para garantir a segurança alimentar da população das grandes e pequenas cidades.

A agricultura urbana e periurbana pode ser definida como a produção de plantas e criação de animais em áreas urbanas e periurbanas, independentemente da escala, indo desde jardins até espaços cultivados maiores (BERGES et al., 2014; THEBO et al., 2014; DIELEMAN, 2017). Assim, representa os sistemas alimentares que compreendem o funcionamento de uma cadeia de produção e consumo, integrando aspectos da nutrição, processamento e embalagem, distribuição e venda, e, por fim, o consumo propriamente dito (FUENTES et al., 2015).

A agricultura urbana pode assumir inúmeras formas, incluindo pequenas fazendas urbanas, produção de alimentos em conjuntos habitacionais, compartilhamento de jardins comunitários, loteamentos, jardins de quintal e jardins de cobertura (AYAMBIRE et al., 2019). Também pode se manifestar em estufas no pátio das escolas e em restaurantes, produção de alimentos em espaços públicos, jardinagem de guerrilha, cultivo de hortaliças em sacadas e janelas, entre outros (BURGIN, 2018; DIEHL, 2020).

Por outro lado, a agricultura periurbana pode ser considerada como o conjunto de atividades agrícolas residuais desenvolvidas em áreas de transição entre as cidades ou nas 
proximidades dos centros urbanos (OPITZ et al., 2016; ULM et al., 2019). Correspondendo a extensão das áreas de cultivo a distância de $10 \mathrm{~km}$ a $20 \mathrm{~km}$ da fronteira urbana (THEBO, DRECHSEL, LAMBIN, 2014; AZUNRE et al., 2019). Além disso, são áreas que apresentam menores densidades populacionais e de infraestrutura quando comparadas com áreas urbanas, mas que possuem áreas de terra mais extensas para a agricultura (ZASADA et al., 2011; OPITZ et al., 2016).

Considerando as diferentes formas de agricultura urbana que atendem a demandas alimentares, tem-se uma gama de modelos, tanto para atividades comerciais quanto para atividades sem fins lucrativos, a partir dos quais esta atividade tem sido praticada, conforme se exibe no quadro 1.

Quadro 1 - Formas de agricultura urbana

\begin{tabular}{|c|c|}
\hline $\begin{array}{l}\text { Forma de } \\
\text { saricultura }\end{array}$ & Características \\
\hline Jardins em casa & $\begin{array}{l}\text { Cultivo de alimentos em terras de propriedade privada adjacentes a uma } \\
\text { residência. }\end{array}$ \\
\hline $\begin{array}{l}\text { Loteamento } \\
\text { crescente }\end{array}$ & $\begin{array}{l}\text { Cultivo em pequenas parcelas de terra, geralmente disponibilizadas pelas } \\
\text { autoridades locais - principalmente na natureza hobby (não comercial). }\end{array}$ \\
\hline $\begin{array}{l}\text { Cultivo comum e } \\
\text { hortas } \\
\text { comunitárias }\end{array}$ & $\begin{array}{l}\text { Incluindo comunidade, confiança, bem-estar e habilidades. Esses espaços são } \\
\text { normalmente abertos ao público, gerenciados por grupos de pessoas ao invés } \\
\text { de autoridades locais. }\end{array}$ \\
\hline $\begin{array}{l}\text { Agricultura apoiada } \\
\text { pela comunidade } \\
\text { (CSA) }\end{array}$ & $\begin{array}{l}\text { Comumente periurbana / rural, os alimentos são produzidos em maior escala } \\
\text { do que nas hortas comunitárias, com papéis fortemente delineados entre } \\
\text { produtores e membros da comunidade. Caracterizada por uma relação de troca } \\
\text { que permite que os riscos de crescimento sejam compartilhados de forma mais } \\
\text { igualitária do que em uma relação típica entre produtor-consumidor. }\end{array}$ \\
\hline Comercial & $\begin{array}{l}\text { Produção de alimentos com fins lucrativos. Comercialização por meio de uma } \\
\text { relação típica entre produtor-consumidor (embora o produto seja } \\
\text { frequentemente vendido em uma cadeia de suprimentos, em vez de } \\
\text { diretamente para os consumidores finais). }\end{array}$ \\
\hline Agricultura vertical & $\begin{array}{c}\text { Integração da agricultura intensiva em estruturas urbanas multiusos e } \\
\text { multiníveis, geralmente em base comercial. }\end{array}$ \\
\hline $\begin{array}{l}\text { Paisagismo } \\
\text { comestível }\end{array}$ & $\begin{array}{l}\text { Incorporar árvores frutíferas comestíveis, arbustos ou plantas herbáceas no } \\
\text { projeto da paisagem residencial. }\end{array}$ \\
\hline $\begin{array}{l}\text { Jardinagem na } \\
\text { cobertura }\end{array}$ & $\begin{array}{l}\text { Cultivo de culturas alimentares nos telhados de edifícios domésticos, comerciais } \\
\text { ou municipais. }\end{array}$ \\
\hline $\begin{array}{l}\text { Agricultura urbana } \\
\text { informal }\end{array}$ & $\begin{array}{c}\text { Cultivo oportunista de culturas alimentares para comercialização ou uso em } \\
\text { terras que não estão sujeitas a rigorosa fiscalização fundiária, sendo } \\
\text { predominante nos países em desenvolvimento. }\end{array}$ \\
\hline
\end{tabular}

Fonte: Nicholls et al. (2020). 
A agricultura em pequena escala pode ser igualmente produtiva (se não mais) do que a agricultura em grande escala. Para tanto, a produção total deve ser considerada e não somente a produção advinda de uma única safra, haja vista que, na agricultura em menor escala, é comum o cultivo de várias culturas no mesmo espaço (entre culturas) ou na mesma estação de cultivo (NICHOLLS et al., 2020).

Depois de cultivados, os alimentos ainda podem ser comercializados com comunidades maiores, auxiliando no combate a crises relacionadas à escassez de alimentos, sazonalidade, instabilidade política ou econômica (WARREM et al., 2015). Com o encurtamento da cadeia produtiva, o influxo de produtos agrícolas diminui e as emissões de gases do efeito estufa também. Tem-se ainda a minimização da distância percorrida pelos alimentos, ou seja, a produção aproxima-se do consumo final (LEE et al., 2015).

Entretanto, um dos principais problemas que impede o crescimento da AU comercial é a ausência ou escassez de leis e regulamentos adequados que enquadrem o setor (ORSINI, 2020). No entanto, as autoridades municipais, têm dado pouca ou nenhuma atenção à agricultura, apesar de sua determinação em tornar suas cidades sustentáveis (AZUNRE et al., 2019). Como consequência, a incorporação da AU no sistema alimentar é geralmente lenta, devido à falta de políticas nacionais e locais e estruturas estratégicas (ORSINI, 2020).

Outro problema está na resistência por parte das pessoas que vivem ao lado da fazenda, que podem ser incomodadas por sujeira e barulho de máquinas, odores de fertilizantes orgânicos, ou podem ter medo de que pesticidas e fertilizantes poluem o ar eles respiram e a água que bebem (GREBITUS et al., 2020). Além disso, atualmente se mantém em terreno financeiro desafiador na concorrência com a agricultura rural convencional, que muitas vezes pode fazer uso de terras baratas e subsídios governamentais (WAIDNER; YANG; HAMM, 2018).

Sendo assim, agricultura urbana só pode ser sustentada se as autoridades municipais integrarem conscientemente a agricultura nos processos de planejamento e zoneamento do uso do terreno da cidade (AZUNRE et al., 2019). Considerando que existem políticas de promoção de espaços verdes na cidade para fins ecológico-ambientais, estético-recreativos e socioeducativos, o mesmo não se pode dizer da agricultura urbana voltada para a produção de alimentos (ORSINI, 2020). Em comparação com a eficiência produtiva da agricultura rural e periurbana, a agricultura urbana permanecerá sempre espacialmente limitada (POULSEN; NEFF; WINCH, 2018). 


\section{Procedimentos metodológicos}

Trata-se de uma pesquisa exploratória, pois visa proporcionar maior proximidade com o problema que está sendo investigado, com vistas a fornecer informações para construir hipóteses no intuito de se obterem explicações para determinados fenômenos e formular novas percepções ou proposições. Quanto à abordagem, utilizou-se o enfoque qualitativo a fim de se obterem subsídios para a elaboração da análise dos resultados.

Foi realizada uma pesquisa de campo junto 18 agricultores que atua com produção orgânica cujas unidades de produção estão localizadas em áreas periurbana de Porto Alegre/RS, delimitando a região de estudo. O instrumento de coleta de dados consistiu em um formulário semiestruturado, composto por questões abertas que contemplavam variáveis relacionadas às abordagens teóricas que fundamentaram esta investigação empírica.

Para a realização das entrevistas junto aos agricultores foram realizados agendamentos prévios, cujo local, data e horário foram escolhidos de acordo com a disponibilidade dos agricultores. Portanto, realizaram-se entrevistas in loco nas propriedades, em feiras e ainda por telefone. Por fim, as entrevistas foram gravadas e transcritas para posterior análise dos dados.

A análise dos dados coletados ocorreu por meio de análise de conteúdo. Os dados foram tabulados em planilhas eletrônicas, criando-se figuras e quadros para melhor visualização. Vale ressaltar que se utilizaram alguns trechos das entrevistas a fim de ilustrar e enriquecer a discussão. Porém, conforme disposto no termo de consentimento livre e esclarecido usado no momento das entrevistas com o intuito de assegurar a privacidade dos respondentes, estes não foram identificados.

\section{Caracterização dos agricultores e das unidades periurbanas de Porto Alegre}

Neste tópico são apresentadas e analisadas as informações referentes aos entrevistados, ou seja, a caracterização dos agricultores e das propriedades orgânicas periurbanas que compuseram a amostra da pesquisa (Quadro 2). Estas informações foram alocadas na primeira seção do questionário aplicado aos agricultores. Com isso, fundamentou-se a análise dos dados no que tange ao entendimento das respostas apresentadas pelos responsáveis, levando em consideração o perfil do objeto de estudo. 
Quadro 2 - Perfil dos agricultores entrevistados

\begin{tabular}{|c|c|c|c|c|c|c|c|}
\hline Agricultor & Idade & Escolaridade & $\begin{array}{l}\text { Início da } \\
\text { atividade }\end{array}$ & $\begin{array}{c}\text { Tipo de } \\
\text { atividade }\end{array}$ & $\begin{array}{l}\text { Membros } \\
\text { da família }\end{array}$ & $\begin{array}{l}\text { Membros que } \\
\text { trabalham na } \\
\text { atividade }\end{array}$ & Sucessão \\
\hline Homem & 69 & Primário & 1999 & Agricultura & 8 & 2 & Não Sabe \\
\hline Homem & 54 & Graduação & 2000 & Agricultura & 1 & 2 & Não \\
\hline Mulher & 56 & Graduação & 1990 & Agricultura & 7 & 6 & Sim \\
\hline Homem & 63 & $\begin{array}{l}\text { Graduação } \\
\text { Incompleta }\end{array}$ & 1950 & $\begin{array}{c}\text { Agricultura/ } \\
\text { Equinos }\end{array}$ & 4 & 2 & Não \\
\hline Mulher & 57 & $\begin{array}{l}\text { Graduação } \\
\text { Incompleta }\end{array}$ & 1976 & Agricultura & 4 & 2 & Sim \\
\hline Mulher & 74 & Graduação & 2000 & Agricultura & 1 & 1 & Não \\
\hline Mulher & 58 & Ensino Médio & 1993 & $\begin{array}{c}\text { Agricultura/ } \\
\text { Avicultura/ } \\
\text { Apicultura }\end{array}$ & 6 & 5 & Não \\
\hline Homem & 74 & Graduação & 1990 & Agricultura & 5 & 2 & Não \\
\hline Homem & 38 & Graduação & 2013 & Agricultura & 3 & 1 & Não Sabe \\
\hline Mulher & 57 & Ensino Médio & 2013 & Agricultura & 5 & 2 & Não Sabe \\
\hline Homem & 59 & Graduação & 2016 & Agricultura & 4 & 4 & Não \\
\hline Homem & 62 & $\begin{array}{l}\text { Fundamental } \\
\text { Incompleto }\end{array}$ & 2003 & Agricultura & 7 & 1 & Sim \\
\hline Homem & 75 & $\begin{array}{c}\text { Primário } \\
\text { Incompleto }\end{array}$ & 1997 & Agricultura & 2 & 1 & Não Sabe \\
\hline Homem & 54 & Ensino Médio & 2015 & Agricultura & 3 & 5 & Não \\
\hline Homem & 29 & Graduação & 2006 & Agricultura & 6 & 2 & Não Sabe \\
\hline Mulher & 66 & Graduação & 1982 & Agricultura & 2 & 2 & Não Sabe \\
\hline Homem & 63 & Graduação & 1989 & Agricultura & 3 & 2 & Não Sabe \\
\hline Mulher & 49 & Graduação & 2004 & Agricultura & 4 & 5 & Sim \\
\hline
\end{tabular}

Fonte: Elaborado pelos autores com base nas entrevistas de campo (2019).

Identificou-se que a agricultura orgânica é praticada, em sua maioria, por homens, sendo 11 entrevistados do sexo masculino e 7 do sexo feminino. Em relação a idade, observa-se o predomínio de indivíduos com faixa etária entre 54 e 59 anos, ao passo que os entrevistados mais idosos possuem faixa etária entre 74 e 75 anos e mais jovens possuem idade compreendida entre 29 e 38 anos. As fazendas urbanas, por outro lado, são geralmente administradas por jovens empreendedores criados na cidade, com uma formação rural limitada, e muitas vezes são altamente abertos a inovações tecnológicas e técnicas agrícolas inteligentes (ORSINI, 2020).

Apesar da avançada idade, observa-se que ainda existem agricultores que mantém sob seu domínio a gestão da unidade de produção. Geralmente isto ocorre por não haver sucessor ou por convicção que enquanto possuem saúde e disposição para o trabalho, ainda devem tomar as decisões (JANDREY, 2015). Os resultados também mostram o pouco envolvimento dos jovens nesta atividade, o que vem ao encontro de estudos que alertam para o êxodo da população jovem do campo. 
Um aspecto que desperta atenção refere-se à formação educacional, que demonstra que a maioria dos produtores possui curso superior completo. Logo, tal situação pode ser um indicativo de que os produtores buscam conhecimento técnico ou de gestão, havendo predomínio de formação em curso superior na área de engenharia agrícola e agronomia. Os demais entrevistados, possuem formações que não são necessariamente ligadas à produção agrícola, pelo menos não diretamente, como formação na área de administração, pedagogia, engenharia civil, entre outras. Nesse sentido, quando se pensa em preparação profissional, pode-se estimar que a escolaridade é um fator que auxilia, mas não é requisito essencial para a atividade de gestão na agricultura orgânica, pois a principal necessidade está relacionada ao conhecimento da natureza (JANDREY, 2015).

Outro aspecto significativo relacionado ao perfil dos entrevistados é de que seus núcleos familiares são relativamente pequenos, diferentemente do critério comum de famílias numerosas no passado. Assim, a família compõe-se basicamente pelo próprio agricultor e seu cônjuge, apenas três entrevistados possuem filhos que trabalham na atividade. A taxa de fecundidade total para o Brasil passou de 2,09 filhos por mulher, que corresponde ao nível de reposição populacional, em 2005, para 1,72 filhos por mulher em 2015, representando uma queda de $17,7 \%$ neste indicador (IBGE, 2016). Logo, a quantidade relativamente pequena do tamanho da família dos entrevistados influência diretamente em relação ao processo sucessório futuro.

Dos indivíduos entrevistados, os agricultores que não terão sucessores devem esta situação ao fato de que seus filhos não estão, ou não pretendem estar inseridos na atividade agrícola. Parte dos entrevistados criou seus filhos distante de tal atividade e existem também aqueles indivíduos que apesar de criarem seus filhos na atividade agrícola, estes não pretendem dar continuidade. Além disso, alguns entrevistados não souberam responder tal questionamento, pois desconhecem a futura escolha de seus descendentes, que ainda são crianças. Os poucos entrevistados que terão sucessores são porque seus filhos gostam da atividade no campo, buscam formação educacional voltada para atividade de produção e gestão, além de demonstrarem visão otimista em relação ao futuro da agricultura orgânica.

Todos os agricultores entrevistados possuem produções totalmente orgânicas, e foi possível identificar três situações principais que, por sua vez, retrataram as diferentes formas de ingresso na atividade: a dos agricultores que atua com produção orgânica que saíram da agricultura convencional; outros agricultores que sempre produziam de forma orgânica mas não tinham certificação, e; os agricultores que ingressaram na atividade recentemente, ou seja, 
desempenhavam anteriormente atividades não agrícolas. Para Jandrey (2015), a principal motivação para a adesão à agricultura orgânica está relacionada a preocupação com a saúde, seguida pela atividade empreendedora, contribuição para aumento na renda familiar e, também, por opção à um modo de vida sustentável.

Identificou-se que alguns desses agricultores são migrantes de outras regiões do estado e do país, enquanto outros residem no mesmo local que herdaram de seus antepassados. A grande maioria adquiriu a unidade de produção a partir dos anos de 2000, e apenas três entrevistados compraram-na por volta de 1950. As unidades de produção dos herdeiros são decorrentes da divisão de propriedades maiores, objetos de herança familiar.

O tipo de agricultura periurbana encontrado nas unidades de produções corresponde agricultura comercial, onde os sistemas de produções de múltiplas espécies estão presentes em áreas de terra ao redor das casas. Para Pires (2016) a agricultura urbana é importante por sua proximidade com o mercado consumidor urbano, e pelas vantagens comparativas que essa localização oferece, ao permitir a entrega de produtos perecíveis frescos, o acesso a recursos produtivos (água, adubos a partir do lixo orgânico doméstico) e a entidades que fornecem crédito, assistência técnica, informações sobre o mercado e outros.

\subsection{Desafios e tendências da agricultura periurbana de Porto Alegre}

Ao analisar a evolução da agricultura periurbana no decorrer dos anos, os agricultores apresentaram relatos sobre a maneira como eram percebidos por outros agricultores e por familiares. Os resultados obtidos demonstraram que a atividade era vista com descrédito e o alimento orgânico era demandado por parte dos consumidores. Para Schultz (2006), a desconfiança acerca da agricultura orgânica relacionava-se a sua inadequação para manter o processo produtivo e econômico das propriedades.

Com o decorrer da atuação da agricultura orgânica, a conscientização das pessoas em relação a alimentação saudável crescia. Por conseguinte, a procura por alimentos orgânicos aumentava, fazendo com que os agricultores explorassem diferentes canais de comercialização. Além disso, os produtores passaram a utilizar também alternativas para diversificar a produção, não restringindo-se a diversificação da produção de hortifruti, mas também, a possibilidade de integrar outras atividades, como a agroindústria, o turismo rural e a criação de animais.

Por outro lado, foram identificadas respostas que representam outras dimensões para o mesmo questionamento. O retorno financeiro no início da atividade correspondia a um fator 
limitador, de modo que para ser reinvestido na produção, os agricultores dependiam da contratação de mão de obra. Com o melhoramento das condições da atividade, outros membros da família passaram a trabalhar na unidade de produção, ou seja, a agricultura orgânica conseguiu trazer membros da família que estavam em outras atividades.

Nos depoimentos também destacou-se o crescimento da preocupação em relação ao consumo de alimentos saudáveis, sendo que alguns agricultores, antes de produzirem orgânicos, não tinham noção da importância em relação à isso. Através da produção, os agricultores adquiriram mais consciência da importância de consumir alimentos saudáveis, tanto que o alimento produzido não é destinado apenas à comercialização, mas também para o consumo da família. Apesar disso, q percebe-se que o consumo de produtos orgânicos é incipiente na vida das pessoas, no entanto, aqueles que a aderiram reconhecem os benefícios desse tipo de alimento. Para Santos et al. (2017), a agricultura orgânica ainda é uma área relativamente nova no Brasil e no mundo, e que seu grau de importância ainda está em plena expansão. Assim, novos incentivos são fundamentais e esperados para o setor.

O acesso a determinados benefícios é levado em consideração para a definição das principais mudanças em relação a atual situação da agricultura orgânica. Nesse sentido, os incentivos governamentais tem permitido que os agricultores se organizem, planejem e ampliem seus produtos com foco nesse mercado. A importância do incentivo ao consumo de produtos orgânicos é notada ao se verificar que algumas políticas públicas se concretizam através das compras governamentais, como no Programa de Aquisição de Alimentos e no Programa Nacional de Alimentação Escolar que citam diretamente a importância da aquisição de produtos orgânicos para a melhoria na qualidade nutricional dos estudantes. Outra política pública consiste na Política Nacional de Agroecologia e Produção Orgânica, sendo resultado da articulação de vários ministérios e da sociedade civil organizada (SANTOS et al., 2017).

Por outro lado, alguns agricutores são pessimistas em relação ao consumo de alimentos orgânicos. Segundo eles, existe informação e as pessoas então conscientes dos beneficíos da alimentação saudável e da importância da preservação ambiental, mas mesmo assim, optam porconsumir alimentos convencionais. O preço elevado e a restrita disponibilidade são os fatores que mais impedem o consumo de alimentos orgânicos. (GREBITUS; PRINTEZUS, 2017; TAVARES;2018).

Outra preocupação está relacionada a sucessão na agricultura orgânica, pois são poucos os agricultores que criaram seus filhos na atividade, e menos ainda aqueles cujos filhos desejam dar continuidade ao trabalho dos pais. Evidenciou-se que a maioria dos jovens quer ir para a 
cidade, estudar, trabalhar, deixando a atividade rural. Desse modo, a única alternativa para muitos agricultores torna-se vender a propriedade. A idade dos agricultores tem aumentado seguindo uma tendência constante durante as últimas décadas, com as gerações mais jovens geralmente deixando suas fazendas familiares para procurar empregos alternativos nas cidades (ORSINI, 2020).

Permanecer no campo não é mais atrativo do ponto de vista de quem deve despender muito esforço físico e não possui as "regalias" da jornada de trabalho de oito horas, como na maioria dos empregos urbanos (KISCHENER et al.,2015). Este é um relato constante de quem ainda vive no campo, ou seja, que as tarefas diárias não são limitadas ao tempo ou automatizadas, principalmente, se o estabelecimento estiver associado à produção animal. Isso pode ser observado na fala do agricultor.

A discussão em torno desta questão assume proporções mais amplas ao incluir no debate o futuro da agricultura orgânica. Essa situação se agrava por meio das percepções de alguns agricultores envelhecidos, que apontam a possibilidade de dar fim à atividade devido seu envelhecimento, haja vista a inexistência de um sucessor. Como possíveis alternativas consideram vender a propriedade preferencialmente para alguém com interesse em prosseguir com a atividade.

Entretanto, para os agricultores que pretendem continuar na atividade e manterem-se no negócio, para o futuro, a perspectiva é aumentar a produção (caixas de abelhas, criação de galinhas) e desenvolver produtos novos (agroindústria para aproveitar as mercadorias quando estão sobrando e adequar nos recipientes). Além disso, demonstram a intenção de inovar os métodos de produção (aquisição de equipamentos que melhorem o desempenho de suas atividades, tanto em relação a mão de obra, quanto na minimização dos efeitos climáticos), preservar as sementes (guardar as sementes), agregar valor ao produto, manter e expandir seus negócios em novos canais de comercialização para estabilizar a produção, bem como criar relações com os consumidores a partir das relações solidárias. Perpectivas futuras são necessários, entretanto, mesmo que os agricultores tenham fortes motivações, a adoção real requer fatores sinérgicos adicionais, incluindo capacidade de adoção pessoal e recursos institucionais (HAN; ARBUCKLE; SCHUCK, 2021). 


\section{Considerações finais}

A proposta central dessa pesquisa foi propiciar uma discussão sobre os desafios e as tendências para a agricultura periurbana de Porto Alegre/RS. Os resultados possibilitaram compreender os aspectos familiares presentes no ambiente rural, bem como a utilização da área, atividades desenvolvidas e produtos produzidos. Foi possível perceber que as unidades de produção buscam usufruir de tais fatores da melhor forma possível, o que promove o sustento da família e preserva os recursos naturais.

A agricultura presente na cidade de acordo com sua tipologia é a agricultura comercial. Essa agricultura era vista com descrédito, mas gradativamente, o mercado foi se expandindo, se modo que os agricultores passaram a utilizar alternativas para diversificar a produção e integrála à outras atividades. $\mathrm{O}$ acesso a determinados beneficíos também é levado em consideração para a definição das principais mudanças em relação a atual situação da agricultura orgânica.

Concernente aos desafios e tendências da agricultura periurbana, percebeu-se otimismo por parte de alguns agricultores frente ao crescimento da preocupação das população em relação ao consumo de alimentos saudáveis. Por outro lado, tais preocupações sociais são consideradas como dotadas de lentidão. Outro fator preocupante corresponde a sucessão futura, pois são poucos os agricultores que criaram seus filhos na atividade, e os jovens desejam trabalhar na cidade, não perpetuando, portanto, as atividades desenvolvidas pelos seus pais.

Em relação aos objetivos e metas estabelecidos pelos agricultores, percebe-se que os agricultores que pretendem continuar na atividade e manterem-se no negócio, intentam maximizar a produção, desenvolver produtos novos e inovar os métodos produtivos, agregar valor ao produto. Também salientaram a questão de manter e expandir seus negócios em novos canais de comercialização para estabilizar a produção, bem como, criar relações solidárias com os consumidores.

No geral, as descobertas mostram que, no geral, os agricultores estão satisfeitos com os resultados da agricultura orgânica. Sugerindo que as autoridades nacionais, governos locais e agricultores também devem promover ativamente a agricultura orgânica para os consumidores, o que trará benefícios para toda a economia.

Durante a realização da pesquisa, constituiu limitação o local escolhido pelos entrevistados para a realização da pesquisa, as entrevistas realizadas no local de comercialização dos agricultores sofreram constantes interrupções, no momento da entrevista 
os agricultores tinham que interromper a entrevista para atender seus clientes.

Para pesquisas futuras acerca da agricultura de Porto Alegre-RS, sugere-se a aplicação do mesmo estudo para os agricultores que estão em processo de transição da agricultura convencional para a agricultura orgânica. Além disso, o impacto das políticas públicas na produção orgânica pode ser mais bem explorado para os diferentes tipos de agricultura, e também como forma de auxílio de novos produtores para acessarem o mercado de orgânicos.

\section{Referências}

AYAMBIRE, A. R. et al. A review of practices for sustaining urban and peri-urban agriculture: Implications for land use planning in rapidly urbanising Ghanaian cities. Land Use Policy, v. 84, p. 260-277, 2019.

AZUNRE, G. A. et al. A review of the role of urban agriculture in the sustainable city discourse. Cities, v. 93, p. 104-119, 2019.

BERGES, R . et al. Urbane landwirtschaft : innovationsfelder für die nachhaltige stadt? Innsula, Müncheberg, p. 1-48, 2014.

BURGIN, S. 'Back to the future'? Urban backyards and food self-sufficiency. Land Use Policy, v. 78, p. 29-35, 2018.

CAMPBELL, Marcia Caton. Building a common table: The role for planning in community food systems. Journal of planning education and research, v. 23, n. 4, p. 341-355, 2004.

DIEHL, J. A.; SWEENEY, E.; WONG, B.; SIA, C.S.; YAO, H.; PRABHUDESAI, M. Feeding cities: Singapore's approach to land use planning for urban agriculture. Global Food Security, v. 26, 2020

DIELEMAN, H. Urban agriculture in Mexico City; balancing between ecological, economic, social and symbolic value. Journal of Cleaner Production, Oxford, v. 163, p. 156-163, 2017.

DUŽí, B.; FRANTÁL, B.; SIMON ROJO, M. The geography of urban agriculture: new trends and challenges. Moravian Geographical Reports, v. 25, n. 3, p. 130-138, 2017.

FAO. Food and Agriculture Organization of the United Nations. Urban Food Agenda. Rome, 2021.

FUENTES, A.N. Urban agriculture in the framework of sustainable urbanism. Temes de Disseni, Barcelona, n. 33, 2017.

GREBITUS, C. et al. Consumers' perception of urban farming-An exploratory study. Frontiers in Sustainable Food Systems, v. 4, p. 79, 2020.

HAN, G.; ARBUCKLE, J. G.; GRUDENS-SCHUCK, N. Motivations, goals, and benefits associated with organic grain farming by producers in lowa, US. Agricultural Systems, v. 191, p. 103175, 2021.

IBGE - INSTITUTO BRASILEIRO DE GEOGRAFIA E ESTATÍSTICA. Síntese de indicadores sociais: uma análise das condições de vida da população brasileira: 2016. Rio de Janeiro: IBGE, 2016. Disponível em: https://biblioteca.ibge.gov.br/visualizacao/livros/liv98965.pdf. Acesso em: 01 jul. 2018. 
JANDREY, W.F. Análise da diversificação e especialização dos sistemas orgânicos de produção sob a ótica da economia de escala e de escopo. 2015. 139 f. Dissertação (Mestrado em Agronegócio) - Programa de Pós-Graduação em Agronegócios, Centro de Estudos e Pesquisas em Agronegócios, Universidade Federal do Rio Grande do Sul, Porto Alegre, 2015.

KISCHENER, M. A.; KIYOTA, N.; PERONDI, M. A. Sucessão geracional na agricultura familiar: lições apreendidas em duas comunidades rurais. Mundo Agrário, Buenos Aires, v.16, n. 33, 2015.

LEE, G. G.; LEE, H. W.; LEE, J. H. Greenhouse gas emission reduction effect in the transportation sector by urban agriculture in Seoul, Korea. Landscape and Urban Planning, Amsterdam, v.140, p. 1-7, 2015.

NICHOLLS, E. et al. The contribution of small-scale food production in urban areas to the sustainable development goals: a review and case study. Sustainability Science, 2020.

OPITZ, I. et al. Contributing to food security in urban areas: differences between urban agriculture and peri-urban agriculture in the Global North. Agriculture and Human Values, v. 33, p. 341-358, 2016.

ORSINI, Francesco. Innovation and sustainability in urban agriculture: the path forward. 2020.

ORSINI, F. et al. Exploring the production capacity of rooftop gardens (RTGs) in urban agriculture: the potential impact on food and nutrition security, biodiversity and other ecosystem services in the city of Bologna. Food Security, Dordrecht, v. 6, n. 6, p. 781-792, 2014.

ORSINI, F. O. et al. Urban agriculture in the developing world: a review. Agronomy for sustainable development, v. 33, n. 4, p. 695-720, 2013.

PIRES, V. C. Agricultura urbana como fator de desenvolvimento sustentável: um estudo na região metropolitana de Maringá. Revista Pesquisa \& Debate, São Paulo, v. 27, n. 2, p. 69-84, 2016.

SANTOS, L. et al. Políticas públicas para o comércio de produtos orgânicos no Brasil. Revista de Ciências Agrárias, Lisboa, v. 40, n. 2, p. 447-459, 2017.

SCHULTZ, G. As cadeias produtivas dos alimentos orgânicos comercializados na feira da agricultura ecológica em Porto Alegre/RS: lógica de produção e/ou distribuição. 2001. 192 f. Dissertação (Mestrado em Agronegócio) - Programa de Pós-Graduação em Agronegócios, Centro de Estudos e Pesquisas em Agronegócios, Universidade Federal do Rio Grande do Sul, Porto Alegre, 2001.

TAVARES, V. S. Alimentos orgânicos: perfil dos consumidores e variáveis que afetam o consumo. 2018. 111 f. Dissertação (Mestrado em Ciência e Tecnologia de Alimentos) Universidade Federal de Viçosa, Viçosa, 2018.

THEBO, A. L.; DRECHSEL, P.; LAMBIN, E. F. Global assessment of urban and peri-urban agriculture: irrigated and rainfed croplands. Environmental Research Letters, Bristol, v.9, n. 11, p.1-10, 2014.

ULM, F. et al. Sustainable urban agriculture using compost and an open-pollinated maize variety, Journal of Cleaner Production, v.212, p. 622-629, 2019.

WARREN, W.; HAWKESWORTH, S.; KNAI, C. Investigating the association between urban agriculture and food security, dietary diversity, and nutritional status: a systematic literature review. Food Policy, v. 53, p. 54-66, 2015. 
UNRIC - CENTRO REGIONAL DE INFORMAÇÃO DAS NAÇÕES UNIDAS. Relatório da ONU diz que é necessário um aumento da produtividade para melhorar a segurança alimentar. Brussels, 2019.

ZASADA, I. Multifunctional peri-urban agriculture: a review of societal demands and the provision of goods and services by farming. Land Use Policy, Guildford, v. 28, n. 4, p. 639-648, 2011. 